\title{
Dynamics of Mini-box Service Retailers' Store Network Management
}

\author{
Taku Kato $^{1}$ \& Kyoichi Kijima ${ }^{2}$ \\ ${ }^{1}$ Faculty of Social Sciences, Kyorin University, Tokyo, Japan \\ ${ }^{2}$ Department of Value and Decision Science, Tokyo Institute of Technology, Tokyo, Japan \\ Correspondence: Taku Kato, Department of Social Sciences, Kyorin University, 476 Miyashita-cho, \\ Hachioji-shi, Tokyo, 192-8508, Japan. Tel: 81-42-691-0011. E-mail: takukato@29109.jp
}

Received: November 9, 2012

Accepted: December 4, 2012

Online Published: December 7, 2012

doi:10.5539/ibr.v6n1p54

URL: http://dx.doi.org/10.5539/ibr.v6n1p54

\begin{abstract}
Service retailers have to develop a large number of outlets to cover geographic markets and they also have to manage their store networks effectively. However, they are not studied enough both what types of strategic options for store network management are there in the domestic context and how the way of store network management affect corporate performances depending on their situation. This research attempts to clarify the relationship between market expansion strategies of service retailers and their corporate performances by analyzing 51 Japanese listed food service firms as well as to give some implications regarding how they should manage store networks to attain the highest profitability and efficiency. Main results are (1) It is assured over time that Proactive Expansion and Dispersed National Expansion are more profitable and more efficient in using assets to generate earnings compared to Local Concentration, and (2) Proactive Expansion has been the most profitable strategy, while Dispersed National Expansion became the most efficient strategy in using assets to generate earnings instead of Proactive Expansion in these two years.
\end{abstract}

Keywords: store network management, mini-box service retailer, dynamics, food service business, Japan

\section{Introduction}

The concept of "Mini-box service retailers" is introduced by Kato and Kijima (2012). They sell primary services that production and consumption are required to occur simultaneously, so they need to develop many independent outlets when they wish to increase the market coverage of their store network. There are vast varieties of services that mini-box service retailers offer, e.g. restaurants, real estate agents, fitness centers, child-care centers, language schools, banks and automobile repair shops, laundry services, just to name a few examples. They have to grasp their stores as a network and they should manage the store network efficiently, because store network management is the key determinant of corporate growth and performance. Store network management seems to have both aggressive and conservative dimensions. The aggressive dimension contains the store development activity by opening new outlets both to expand the coverage area of the store network and to increase the density of existing store network. As a result of such aggressive store network management, it is not unusual to find mini-box service retailers with more than a thousand outlets within one domestic market. Unlike big-box retailers that open only one or two stores in each market, mini-box service retailers optimize store locations by developing ten or more outlets. They routinely conduct site selections in order not to miss good locations, e.g. a site located along the main streets or intersections with a large number of pedestrians, or a site which is close to other commercial facilities with high visitor transactions, since such locations are predetermined and usually highly limited in availability. They also have to balance new store development between entering into new markets and increasing store intensity in existing markets. Those kinds of aggressive store development approaches should be balanced strategically and the effectiveness should be evaluated by the corporate performance. On the other hand, the conservative dimension of store network management includes the reconstruction of the existing store network by relocating or closing existing outlets in the worst case. It may become necessary for firms to consider the closing of unprofitable existing stores when market environment changes dramatically in the trade area of a certain outlet, or when firms had made a mistake in selecting sites. Sometimes firms consider relocating existing stores when they have opportunities to develop new outlet in better locations that are close to the existing store. Even the firms which have already developed store networks to a certain level might need to make changes with their strategy and consider reconstruction of their existing store networks. Managers of the service firms are always in search for how they should manage their store networks in 
order to be the top brand in the country as well as to improve corporate performances. Along with the evolving stages of the corporate growth, they tend to face situations where they need to make decisions on both aggressive store expansion strategy and conservative strategy in parallel. Although some studies have been conducted regarding the growth strategy of service firms in the service marketing field, those studies do not seem to be directly applicable to these situations. Some authors have recommended firms to build area dominance in a certain geographic market because profitability can be securely maximized. Relationship between the intensity of distribution network and the choice of consumers has been examined by Bucklin et al. (2008), while Tobla, A. H (2011) had investigated how brand preferences and loyalty are influenced by distribution intensity. Knoben et al. (2008) studied how relocation of existing store affects firms' financial results, in which how firms formed their store networks is hardly discussed. Some authors have shown the criteria when firms choose a country when going global and dealt with geographic expansion in international context, e.g., Kogut, B (1985a), Kogut, B (1985b), Elango, B (2000), Hollensen, S (2004), and so on. Therefore, the lack of knowledge regarding how firms should grow in the domestic context disable the firms to judge more confidently on their store network management activities. This research attempts to show classified strategic options for store network management and how each strategic option would be related to financial results of the firms. Section 2 shows theoretical background of store network management and formulates hypotheses regarding the influence of store network management on corporate performances. Then, data and empirical results are described in Section 3, and strategic implications are mentioned in Section 4. Finally, conclusion and the agenda for future research are shown in Section 5.

\section{Theory Development}

\subsection{Framework for Store Network Management}

The analytical framework of mini-box service retailers' store development strategies are shown as a preparatory study in Kato \& Kijima, 2012, where the concept of store concentration and the way of choosing markets are introduced into the existing growth opportunity framework by Levy and Weitz (2004) as well as the profitable path of expansion through the analysis of 52 Japanese food service companies listed in Japan.

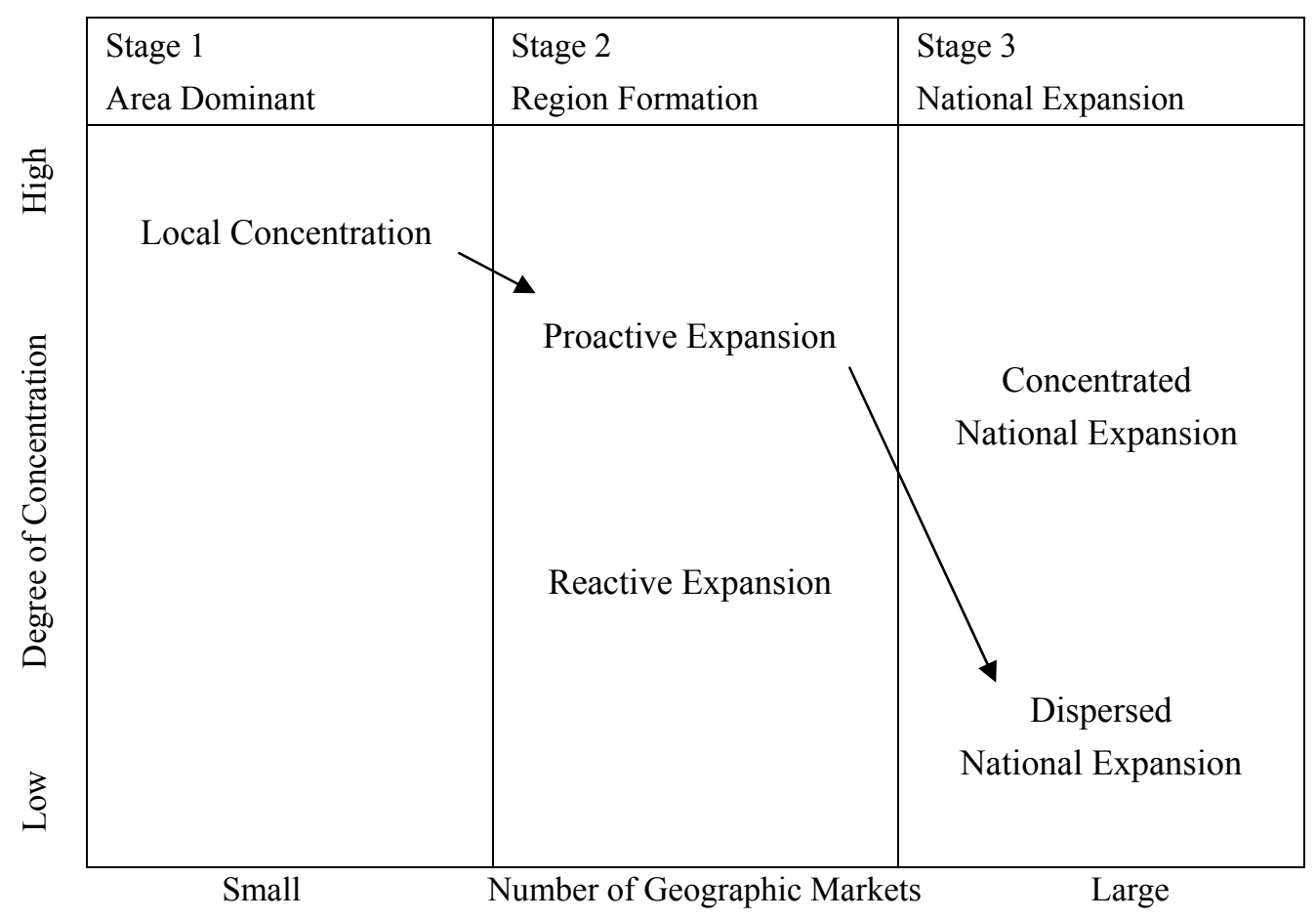

Figure 1. Market Expansion Strategies for Mini-Box Service Retailers

Source: Figure 2 in Kato and Kijima (2012) modified by authors.

Figure 1 shows five categories of market expansion strategies of mini-box service retailers. The vertical axis indicates the degree of store concentration to a specific geographic market, while the horizontal axis indicates the number of geographic markets where the firms have already opened at least one outlet. It is assumed that attempting to expand their outlets nationally follows three stages. At the first stage, firms should establish area 
dominance by concentrating outlets in a small number of geographic markets. Therefore, Local Concentration with high degree of concentration as well as small number of geographic markets is often the starting point of store network development. At the next stage, firms should try to form region which is in the middle of area and nation in terms of space. There are two types of strategies in this stage: Proactive Expansion and Reactive Expansion. The former is the strategy which strategically selects new geographic market with high sales potential, where their new stores would be added mainly. Compared to Local Concentration, degree of concentration is lower, but is kept in relatively high level. The latter is the strategy which tries to cover more number of geographic markets at the early stage of expansion with decreasing degree of store concentration dramatically. Number of geographic markets is expected to be larger than that of Proactive Expansion. At the final stage, firms would enjoy national presence by covering market nationally, and so the number of geographic markets is the highest among all the stages, and there two strategies are classified when the difference in degree of concentration is taken into account: Concentrated National Expansion and Dispersed National Expansion. The former is the strategy which keeps degree of concentration high with less effort to add outlets into geographic markets where firms entered recently, while the latter is the one which make degree of concentration lower with more effort to disperse outlets nationally. The profitable path of expansion is also suggested in Firure 1 by using arrows because it is proved that firms adopting both Proactive Expansion and Dispersed National Expansion are found to be more profitable than those adopting Local Concentration.

However, it should be admitted that the study by Kato and Kijima (2012) was rather preliminary due to some reasons. First, shown result was based on the single point data as of fiscal year 2009, therefore it could not show whether the result would be stable or not over time. Then, because single point data was used, the main discussion there was limited to the aggressive aspects of store development activities involving new store developments, while as we mentioned earlier, the store network management has also conservative aspects including relocation and closing of existing stores. Finally, extremely limited aspect of financial result was discussed while financial indicators other than profitability should also be analyzed. Reflecting these drawbacks, this research would attempt to show whether the result of the study by Kato and Kijima (2012) would be stable or not over time by using two-point data. We re-classified firms by store development strategy according to new store development data as of July 2012 and re-examined the effect of their store expansion strategies on their financial results as of FY 2012 by analyzing 51 Japanese food service companies listed in Japan. In addition to profitability, this research focuses on firms' efficiency in using their assets to generate profits because store management activity seems to be equal to investment activity. This research also attempted to analyze the effects of strategic changes on corporate performances between two points of time. Some strategic changes may be aggressive with market expansion along with new store developments, while other strategic changes may be conservative with market shrinking along with closing existing stores. It could be expected that promoted framework could analyze wider range of store network management of mini-box service retailers.

\subsection{Hypothesis}

First of all, it should be examined whether the profitable path of expansion I suggested in Figure 1 is robust or not over time, because this is merely based on the single point data as of fiscal year 2009, so it should be shown whether the results remain stable or not as time passes. Therefore, regarding profitability, the following hypothesis 1, 2 and 3 should be formed.

Hypothesis 1: Proactive Expansion is higher than Local Concentration in terms of profitability.

Hypothesis 2: Dispersed National Expansion is higher than Local Concentration in terms of profitability.

Hypothesis 3:The rank order of the strategies in terms of profitability is conjectured to be: Proactive Expansion, Dispersed National Expansion, Concentrated National Expansion, Local Concentration and Reactive Expansion.

Store development activity is equal to the investment activity because it is required to spend the money on new store development or sometimes on maintenance of existing stores in order to generate profit. Therefore, the firms need to evaluate the efficiency of investment on those properties by utilizing return on assets (ROA). It seems to be expected that ROA of each outlet could vary depending on its location in retail business (Aaker, 1998), which could also be true with mini-box service retailers. As service firms, they have to make sure that customers could receive the same service at each of their outlets through standardization by establishing a set of rules and procedures, making sure that those are implemented consistently. (Levy \& Weitz, 2004) They also should try to standardize store formats, properties and equipment in each outlet as much as possible. As a result, it is expected that the total amount of investment for each outlet could be standardized, so that the more outlets the firms have, the lower the cost for store development activities become. When such a standardization of 
investment among outlets is achieved, profitability could be the key determinant of ROA. Therefore, when we consider the relationship between store development strategies and ROA, hypothesis 4 and 5 could be formed as follows.

Hypothesis 4: Proactive Expansion is higher than Local Concentration in terms of ROA.

Hypothesis 5: Dispersed National Expansion is higher than Local Concentration in terms of ROA.

Considering that the amount of investment for each outlet is expected to decrease with economy of scale as firms develop more outlets, Proactive Expansion strategy is expected to be relatively higher than Dispersed National Expansion strategy in terms of store development investment for each outlet although Proactive Expansion strategy is also expected to be higher than Dispersed National Expansion strategy in terms of profitability. It could be expected that Proactive Expansion strategy is "higher-cost, higher-return" and Dispersed National Expansion is "lower-cost, lower return". Though it is difficult to hypothesize which strategy is more efficient in using its assets to generate earnings, we hypothesized that positive effect of profitability is more important factor for ROA than the positive effect of scale economy of investment. Therefore, hypothesis 6 could be formed as follows.

Hypothesis 6: The rank order of the strategies in terms of ROA is conjectured to be: Proactive Expansion, Concentrated National Expansion, Dispersed National Expansion, Local Concentration and Reactive Expansion.

\section{Dynamics in Japanese Food Service Industry between 2009 and 2012}

\subsection{Data Collection and Classification by Strategy}

51 Japanese food service firms, which are focusing on food service exclusively as well as listing their stocks, are selected as research subjects. Store list of each firm is collected from each firm's web-sites or the annual reports which are publicly disclosed. A unit in counting the number of geographic markets is the prefecture. Firms which limit its market up to ten prefectures, which are connected geographically, are classified in Local Concentration. Firms which enter into up to three prefectures with high sales potential intensively as well as keep HHI over 1000, is classified in Proactive Expansion. Firms which enter into more than four prefectures with high sales potential as well as keep HHI over 1000 is classified in Concentrated National Expansion. Firms are classified in Dispersed National Expansion if they enter into more than four prefectures with high sales potential as well as their HHI is under 1000. Firms which are classified into neither strategy are classified in Reactive Expansion. Table1compares the characteristics of each strategy between 2010 and 2012. As indicators for firms' financial results, the average of operating income to sales ratio and ROA between both the period of 2005 and 2010 and the period of 2007 and 2012, are calculated based on the financial statements published by each firm.

Table 1. Characteristics by Strategies

\begin{tabular}{|c|c|c|c|c|c|c|c|c|c|c|}
\hline \multirow{2}{*}{$\begin{array}{l}\text { Type of Strategy } \\
\text { Year }\end{array}$} & \multicolumn{2}{|c|}{$\begin{array}{l}\text { Local } \\
\text { Concentration } \\
\end{array}$} & \multicolumn{2}{|c|}{$\begin{array}{l}\text { Proactive } \\
\text { Expansion } \\
\end{array}$} & \multicolumn{2}{|c|}{$\begin{array}{l}\text { Reactive } \\
\text { Expansion } \\
\end{array}$} & \multicolumn{2}{|c|}{$\begin{array}{l}\text { Concentrated } \\
\text { National Expansion }\end{array}$} & \multicolumn{2}{|c|}{$\begin{array}{l}\text { Dispersed } \\
\text { Expansion } \\
\end{array}$} \\
\hline & 2010 & 2012 & 2010 & 2012 & 2010 & 2012 & 2010 & 2012 & 2010 & 2012 \\
\hline Number of Firms & 10 & 10 & 12 & 10 & 7 & 7 & 8 & 10 & 14 & 14 \\
\hline Average of Store counts & 123.0 & 132.8 & 156.6 & 134.3 & 246.4 & 183.4 & 480.5 & 621.5 & 833.3 & 885.2 \\
\hline $\begin{array}{l}\text { Average of the number of } \\
\text { Prefectures entered }\end{array}$ & 6.0 & 5.8 & 12.3 & 10.3 & 19.9 & 21.4 & 33.1 & 31.8 & 38.2 & 42.5 \\
\hline Average of HHI & 3894 & 4001 & 3373 & 374 & 1833 & 1942 & 1726 & 1755 & 684 & 665 \\
\hline $\begin{array}{l}\text { Average of Operating income to } \\
\text { sales ratio }(\%)\end{array}$ & 4.0 & 2.9 & 7.8 & 7.1 & 2.9 & 2.4 & 4.6 & 4.5 & 7.1 & 6.9 \\
\hline Average of ROA (\%) & 6.5 & 4.9 & 11.4 & 10.3 & 4.1 & 4.1 & 7.7 & 6.7 & 10.6 & 11.1 \\
\hline
\end{tabular}

\subsection{Analysis}

To determine the effects of the type of expansion strategies on both profitability and ROA, the following regression model werespecified:

$$
\begin{gathered}
\text { Profitability }=a+b \operatorname{Cog} s+c P E+d R E+e C N E+f D N E \\
\text { Profitability }=a+b P E+c R E+d C N E+e D N E \\
\text { Return on Assets }=a+b \operatorname{Cog} s+c P E+d R E+e C N E+f D N E \\
\text { Return on Assets }=a+b P E+c R E+d C N E+e D N
\end{gathered}
$$


Cogs means the cost of goods sold to sales ratio. PE, RE, CNE, DNE represent dummy variables which are equal to 1 for Proactive Expansion, Proactive Expansion, Reactive Expansion, Concentrated National Expansion and Dispersed National Expansion for each, where the reference group is Local Concentration. Results are shown in Table 2 and Table 3.

Table 2. Results of Regression Analysis: Profitability

\begin{tabular}{|c|c|c|c|c|c|c|c|c|}
\hline \multirow[t]{3}{*}{ Regression } & \multicolumn{4}{|l|}{ (1) } & \multicolumn{4}{|l|}{ (2) } \\
\hline & \multicolumn{2}{|l|}{2010} & \multicolumn{2}{|l|}{2012} & \multicolumn{2}{|l|}{2010} & \multicolumn{2}{|l|}{2012} \\
\hline & Coef. & t value & Coef. & t-value & Coef. & t value & Coef. & t-value \\
\hline Cogs & -0.096 & -1.39 & $-0.128 *$ & -1.85 & - & - & - & - \\
\hline PE & $4.090 * * *$ & 2.46 & $4.587^{* *}$ & 2.54 & $3.800 * *$ & 2.28 & $4.250^{* *}$ & 2.31 \\
\hline RE & -0.797 & -0.42 & 0.357 & 0.18 & -1.050 & -0.55 & -0.451 & -0.22 \\
\hline $\mathrm{CNE}$ & 1.116 & 0.60 & 2.229 & 1.24 & 0.613 & 0.33 & 1.574 & 0.87 \\
\hline DNE & $3.895 * *$ & 2.37 & $5.137 * * *$ & 2.86 & $3.121 *$ & 1.93 & $4.051^{* *}$ & 2.34 \\
\hline cons & $6.824 * * *$ & 2.84 & $6.636^{* * *}$ & 2.80 & $3.950 * * *$ & 3.20 & $2.880^{* *}$ & 2.28 \\
\hline R-squared & 0.231 & & 0.249 & & 0.198 & & 0.194 & \\
\hline Adj-R-squared & 0.145 & & 0.165 & & 0.128 & & 0.124 & \\
\hline $\mathrm{N}$ & 51 & & 51 & & 51 & & 51 & \\
\hline
\end{tabular}

Note: $* \mathrm{p}<0.1, * * \mathrm{p}<0.05, * * * \mathrm{p}<0.01$.

In Table 2, two regression models are compared between 2010 and 2012. Coefficients of PE and DNE are positive as well as significant at least 5\% level in regression 1 in both 2010 and 2012 . The same result is also identified when Cogs is excluded from Regression 1. Therefore Hypothesis 1 and 2 are supported. Regarding Reactive Expansion and Concentrated National Expansion, both of coefficients are not statistically meaningful. However, their signs are as previously expected, that is, Reactive Expansion has negative one while Concentrated National Expansion has positive one. Though the rank order of the strategies adopted by firms in terms of profitability changed between 2010 and 2012 in regression 1, where Dispersed National Expansion showed the highest profitability and Proactive Expansion came to second in 2012, it does not seem to change in Regression 2. It is hard to conclude there was a change in the rank order the rank order of the strategies adopted by firms in terms of profitability. Therefore, hypothesis 3 was also supported.

Table 3. Results of Regression Analysis: ROA

\begin{tabular}{|c|c|c|c|c|c|c|c|c|}
\hline \multirow[t]{3}{*}{ Regression } & \multicolumn{4}{|l|}{ (3) } & \multicolumn{4}{|l|}{ (4) } \\
\hline & \multicolumn{2}{|l|}{2010} & \multicolumn{2}{|l|}{2012} & \multicolumn{2}{|l|}{2010} & \multicolumn{2}{|l|}{2012} \\
\hline & Coef. & $\mathrm{t}$ value & Coef. & t-value & Coef. & $\mathrm{t}$ value & Coef. & $\mathrm{t}$-value \\
\hline Cogs & 0.003 & 0.03 & -0.108 & -1.04 & - & - & - & - \\
\hline PE & $4.898 * *$ & 1.99 & $5.692 * *$ & 2.15 & $4.907 * *$ & 2.03 & $5.410 * *$ & 2.05 \\
\hline RE & -2.382 & -0.84 & -0.156 & -0.05 & -2.374 & -0.85 & -0.834 & -0.29 \\
\hline $\mathrm{CNE}$ & 1.199 & 0.43 & 2.292 & 0.87 & 1.215 & 0.45 & 1.744 & 0.68 \\
\hline DNE & $4.116^{*}$ & 1.64 & $7.114 * * *$ & 2.70 & $4.140^{*}$ & 1.77 & $6.203 * *$ & 2.50 \\
\hline _cons & $6.371 *$ & 1.79 & $8.107 * *$ & 2.25 & $6.460 * * *$ & 3.62 & $4.920 * *$ & 2.64 \\
\hline R-squared & 0.190 & & 0.294 & & 0.190 & & 0.201 & \\
\hline Adj-R-squared & 0.010 & & 0.216 & & 0.119 & & 0.131 & \\
\hline $\mathrm{N}$ & 51 & & 51 & & 51 & & 51 & \\
\hline
\end{tabular}

Note: ${ }^{*} \mathrm{p}<0.1,{ }^{* *} \mathrm{p}<0.05,{ }^{* * *} \mathrm{p}<0.01$.

In Table 3, two more regression models are compared between 2010 and 2012.Coefficients of PE and DNE are positive as well as significant at least 10\% level in regression 3 in both 2010 and 2012. The same result is also identified when Cogs is excluded from Regression 3. Therefore Hypothesis 4 and 5 are supported. Regarding Reactive Expansion and Concentrated National Expansion, both of coefficients are not statistically meaningful. However, their signs are as previously expected, that is, Reactive Expansion has negative one while Concentrated National Expansion has positive one. These results are in common with those of profitability. However, the rank order of the strategies adopted by firms in terms of ROA changed between 2010 and 2012, where Dispersed National Expansion came to first instead of Proactive Expansion. Therefore, hypothesis 6 was not supported. 


\section{Discussion and Implications for Management}

\subsection{Discussion}

It is proved that it has been stable over time between 2010 and 2012 that both PE and DNE are more profitable as well as better ROA than LC. The profitable path of expansion suggested in Figure 1 seems to have robustness. It is also shown that a difference occurs in the rank order of the strategy between profitability and efficiency in using assets in 2012. Though the rank order of the strategies adopted by firms in terms of ROA in 2010 was the same as that of profitability, one change was found with 2012 rank order in terms of ROA: Dispersed National Expansion became the first, overtaking the position of Proactive Expansion. Two possible reasons for this change could be considered. Firstly, because population shift to urban market is accelerating recently and rural markets are becoming more desperate to secure the customer traffic, firms that won popularity in big cities are often given financial advantages when they first enter the rural markets. For example, when such firms open their first outlets as tenants of the shopping malls located in the rural market, in many cases they are given extremely favorable conditions in terms of rent and initial investments. Developers of shopping malls might even share some parts of initial store development investments expecting not only the high sales of the new tenants after opening but also the additional number of customers visiting the shopping mall itself who are attracted to the new tenants. Secondly, many recent store developments by Dispersed National Expansion might include stores on the roadside in the suburbs or rural market. Roadside seems to have some advantages financially in Japanese food service. Firms could expect high average ticket because main customers of the roadside stores tend to be family users and workers especially blue-color who are expected to spend more money at the restaurant than customers in urban markets, while rent fee per square feet is lower than that of street stores in urban area.

Dynamic aspects of Store Network Management framework should also be discussed. Through the examination of the firms belonging to each strategic type, it was found that eight firms in total have changed their store development strategy between 2010 and 2012. Two firms that were adopting Proactive Expansion in 2010 expanded their market in different ways. AkindoSushiro moved to Dispersed National Expansion by both doubling the number of prefecture entered to 40 and lowering HHI dramatically to between seven hundred and eight hundred. It opened 134 new outlets in these two years. On the other hand, Osho Food Service moved to Concentrated National Expansion. It also developed about one hundred new stores in the same term. By entering seven more new prefectures, its total number of prefecture entered reached 35, and although the degree of store concentration was lowered accordingly, HHI has been kept above 1000. Judging from our research results, it could be expected that moving from Proactive Expansion to Dispersed National Expansion or Concentrated National Expansion should lead to lower profitability. However, unlike our expectations, profitability of both AkindoSushiro and Osho Food Service increased. AkindoSushiro increased profitability by $0.1 \%$ from $7.6 \%$ to $7.7 \%$ and Osho Food Service by $0.4 \%$ from $12.1 \%$ to $12.5 \%$. Possible factors that contributed to add profitability are as follows. AkindoSushiro exceptionally accelerated its store development speed dramatically these two years, which presumably increased their brand awareness throughout Japan. The speed of store development is considered to affect the momentum of the brand. Osho Food Service seems to have prioritized to open up geographically new markets these two years and their first store in rural region could have attracted much more customers initially than expected usually. These elements could be considered to have given favorable effects on their corporate performances. Ringer Hut moved from Reactive Expansion to Concentrated National Expansion. They expanded their market to 37 prefectures by entering eight new prefectures while HHI was maintained above 1000.Considering the result that profitability is higher in firms adopting Concentrated National Expansion than in firms adopting Reactive Expansion, it could be expected that moving from Concentrated National Expansion to Reactive Expansion should lead to higher profitability. Operating Income to Sales Ratio of Ringer Hut increased $1.5 \%$ from $1.7 \%$ to $3.2 \%$, which is consistent with our expectation. Monogatari Corporateion moved from Concentrated National Expansion to Dispersed National Expansion. The firm lowered HHI to below 1000 by opening new outlets in four new prefectures. Following the expectation from our research results that moving from Concentrated National Expansion to Dispersed National Expansion should lead to higher profitability, the profitability of The Monogatari Corporation increased $0.1 \%$ from $7.6 \%$ to $7.7 \%$.

While four firms mentioned above developed their store network aggressively and enjoyed their positive financial results, GenkiZushi, Colowide and Saizeriya moved from Dispersed National Expansion to Concentrated National Expansion by increasing their HHI. Genki-Zushi decreased the number of stores in prefectures with relatively small market potential. On the contrary, Colowide and Saizeriya decreased the number of stores in prefectures with high market potential. Regarding profitability, Genki-Zushi dropped by $0.1 \%$, which is consistent with our expectation. However, Colowide's profitability was almost unchanged and 
Saizeriya increased its profitability by $0.9 \%$, which are not consistent with our expectations.

Pepper Food Service, which was in Concentrated National Expansion in 2010, moved to Reactive Expansion. The company seems to lack a closing policy of existing stores assuming from the fact that the companysh rank their coverage area as well as decreased HHI. As expected from our framework, the company's profitability decreased by $0.3 \%$.Ten firms that were included in Local Concentration in 2010 did not change their strategy. All firms except Towa Food Service increased HHI, while Friendly and Amiyaki-Teishrank their operating areas.

\subsection{Implications for Management}

What could be implemented from the research results based on the store network management framework is that Proactive Expansion strategy should be recommended if firms put priority on the profitability while Dispersed National Expansion should be recommended if they put priority on improving the efficiency of total assets. The store network management framework could give some guidelines to management of mini-box service retailers. Regarding aggressive aspect of the store network management, the ideal growth path could be explained as follows: small or newly established firm including foreign firms wishing to enter the country which are still in initial stage in their growth path should make the strong area dominance in very limited number of geographic market. If they expand market quickly at the stage by adopting Reactive Expansion, both profitability and efficiency would be worsened. It should be suggested that firms should "not" open outlets in wider area randomly at the initial stage even if there are opportunities to do so. If firms succeed in making area dominant at the initial stage, they should form regions by expanding to wider areas. At this stage, firms need to both select a few more geographic markets with high sales potential and add outlets exclusively, if they wish to improve profitability and efficiency. If firms fail to add stores after entering high sales potential market, their store network could become high-cost structure due to high rent fee, high logistic cost and so on. If firms succeed in forming regions in a few major markets, they could expand their store network nationally. If firms wish to improve the efficiency of total assets with keeping profitability at high level, they should select geographic markets with enough market potential to add some more outlets. What should be avoided is to scatter outlets by opening a small number of outlets in isolation. Firms should gradually decrease store concentration by opening more outlets in every geographic market where remains room for store development remains, otherwise, their store network could become higher-cost structure mainly due to the high logistic cost.

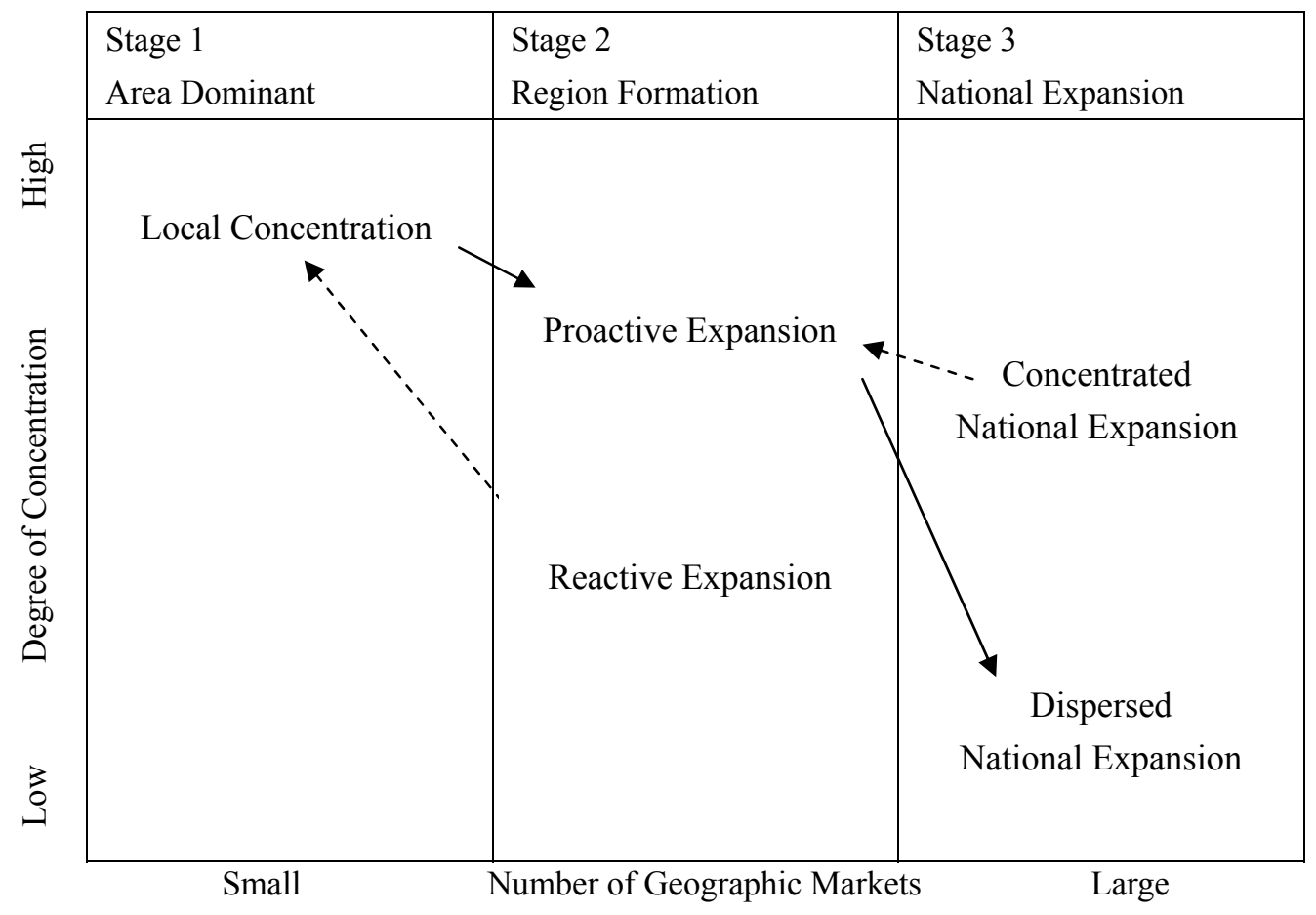

Figure 2. Store Network Management for Mini-Box Service Retailers

By using the store network management framework in Figure 2, it would also become possible for firms that have already developed their store network to a certain extent to reconstruct them. There seems to be some firms which have already expanded their store networks to a certain level in their own domestic markets. 
Some firms might have already opened outlets in wider area at the initial stage, leading to lower profitability and ROA. Some firms might have already expanded nationally by opening a small number of outlets in isolation, also leading to lower profitability and ROA, too. For such firms, it might be suggested to move back to Local Concentration or Proactive Expansion once beforeexpanding their store networks additionally by reallocation of some outlets through closing or relocation as dot arrows in Figure 2 shows.Firms are also able to modify their strategic plans for conservative aspect of the store network management by using the store network management framework.

\section{Conclusion and Implications for Future Research}

By examining dynamics and taking ROA into account in addition to profitability, the framework for market expansion strategy in Kato \& Kijima, 2012, seems to be advanced. Proposed store network management framework seems to be helpful for mini-box service retailers in considering both aggressive and conservative aspect of store network management, and in forecasting the dynamic effects of strategic changes on corporate performance over time. Firms have to identify the current situation of their store networks by checking degree of store concentration and how they have expanded in the domestic market so far. The ideal growth path could be a guideline for firms to proceed or to modify their strategy. If firms are on the path, they should go on following the path otherwise they should attempt to get closer to it. This research result seems to be expected to motivate service firms to enlarge their store networks throughout a country aggressively or to modify their strategies in the middle of store network expansion by giving them some guidelines for managing their store networks geographically.

Though we have been focusing mainly on the store development activity in the framework explaining how firms should manage store networks effectively, in order to enrich this study, further classification of strategies should be pursued considering new store formats or new store brands. When firms that operate large-scale outlets in suburban markets try to move into urban markets, they have to consider developing smaller store formats because it is usually quite difficult to secure profitability with existing store format given the much higher rent in urban markets. When firms found some sites in a certain market but at the same time cannibalization of sales could be expected if they open outlets with same store brand at the same time, they might consider acquiring all sites by opening stores under different brands, because otherwise competitors would have opportunities to open outlets at the sites where are given up. Considering these facts, another critical element of the growth strategy could be the development of new store formats or new store brands. Also, other corporate performance data e.g., risk factor should be analyzed in the same framework to evaluate the store network management of firms more comprehensively. Local Concentration strategy is considered to be accompanied by vulnerability due to concentration of geographic area in which an entity conducts its operations. When natural disasters e.g. earthquake, tsunami, eruption of volcano, localized heavy rain or snow, typhoon, epidemics, etc. hit a certain area where firms concentrated their outlets, economic performance of the firms would be heavily damaged. It should also be analyzed how the vulnerabilities of profitability and ROA are affected by the strategic type. Then, this study has a considerable potential to be extended and tested in different environments. In future researches, application of this framework to other fields in the same country would highlight factors which are proper to the industry. On the other hand, application of this framework to other countries in the same field would highlight factors which are proper to the country. Finally, what practitioners would be interested in could be how to execute the strategy suggested by the framework for store network management depending on their growth stage. In service marketing literatures, much effort seems to have been focusing on relationship between firms and customers. However, considering service firms have to develop store networks for corporate growth, they have to manage the relationship between actors other than customers systematically. More researches would be required to identify actors other than customers which mini-box service retailers should establish relationships depending on their growth stages.

\section{References}

Aaker, A. D. (1998). Strategic Market Management (5th ed.). John and Wiley \& Sons, Inc.

Albaum, G., Strandskov, J., Duerr, E., \& Dowd, L. (1994). International Marketing and Export Management. Addison-Wesley Publishing Company.

Ansoff, I. (1965). Corporate Strategy. McGraw-Hill.

Bateson, J. E. G., \& Hoffman, K. D. (1999). Managing Services Marketing. The Dryden Press.

Bucklin, R. E., Siddarth, S., \& Silva-Risso, J. M. (2008). Distribution Intensity and New Car Choice. Journal of Marketing Research, 45(4), 473-486. http://dx.doi.org/10.1509/jmkr.45.4.473 
Buhner, R. (1987). Assessing International Diversification of West German Corporations. Strategic Management Journal, 8, 25-37. http://dx.doi.org/10.1002/smj.4250080104

Carman, J. M., \& Langeard, E. (1980). Growth Strategies for Service Firms. Strategic Management Journal, 1(1), 7-22. http://dx.doi.org/10.1002/smj.4250010103

Doyle, P., \& Corstjens, M. (1983). Optimal Growth Strategies for Service Organizations. Journal of Business, 56(3), 389-405. http://dx.doi.org/10.1086/296207

Elango, B. (2000). An Exploratory Study into the Linkages between Corporate Resources and the Extent and Form of Internationalization. American Business Review, 18, 12-26.

Furhan, W. E. (1972). Pyrrhic Victories in Fights for Market Shares. Harvard Business Review, 70(5), 100-107.

Gohshal, S. (1987). Global Strategy: An Organizing Framework. Strategic Management Journal, 8, 425-440. http://dx.doi.org/10.1002/smj.4250080503

Hollensen, S. (2004). Global Marketing. Prentice Hall Publishing.

Hut, M. D., Tarasi, C. O., \& Walker, B. A. (2012). Financial Portfolio Theory and Customer Management: Insights and Research Direcions. Handbook of Marketing and Finance edited by S. Ganesan. Edward Elgar.

Jennet, J. P., \& Hennessey, H. D. (2001). Global Marketng Strategies. Houghton Mifflin Company.

Johnson, R. (1996). Achieving Focus in Service Organizations. The Service Industries Journal, 16(January), 10-20. http://dx.doi.org/10.1080/02642069600000002

Jones, K., \& Simmons, J. (1990). The Retail Environment. Routledge.

Kasper, H., Helsdingen, P. V., \& Gabbott, M. (2006). Service Marketing Management: A Strategic Perspective. John Wiley \& Sons.

Kato, T., \& Kijima, K. (2012). Store Development Strategies of Mini-Box Service Retailers: Analytical Framework and Case Study in Japanese Food Service. International Journal of Marketing Studies, 4(4), 1-13. http://dx.doi.org/10.5539/ijms.v4n4p1

Knoben, J., Oerlemans, L. A. G., \& Rutten, R. P. J. H. (2008). The Effects of Spatial Mobility on the Performance of Firms. Economic Geography, 87(2), 157-183.

Kogut, B. (1985a). Designing Global Strategies: Comparative and Competitive Added Value Chains. Sloan Management Review, 26(4), 15-28.

Kogut, B. (1985b). Designing Global Strategies: Profiting from Operational Flexibility. Sloan Management Review, 27(1), 27-38.

Laulajainen, R., \& Stafford, H. A. (1987). Corporate Geography-Business Location Principles and Cases. Kluwer Academic Publishers.

Levy, M., \& Weitz, B. A. (2004). Retailing Management. McGraw Hill.

Lovelock, C., \& Wright, L. (1999). Principles of Service Marketing and Management. Upper Saddle River, NJ: Prentice Hall.

Montgomery, D. B., \& Urban, G. L. (1969). Management Science in Marketing. Enlewood Cliffs, N. J.: Prentice-Hall.

Palepu, K. G., Healy, P. M., \& Bernard, V. L. (2000). Business Analysis and Valuation: Using Financial Statements (2nd ed.). South-Western College Publishing.

Palmer, A., \& Cole, C. (1995). Services Marketing: Principle and Practice. Prentice-Hall, Inc.

Riddle, D. L. (1986). Service Led Growth. Praeger Publishing.

Simmons, J. W., \& Speck, B. (1988). The Spatial Imprint of Business Strategy. University of Toronto, Department of Geography, Discussion Paper, No. 35.

Tobla, A. H. (2011). The Impact of Distribution Intensity on Brand Preference and Brand Loyalty. International Journal of Marketing Studies, 3(3), 56-66. 